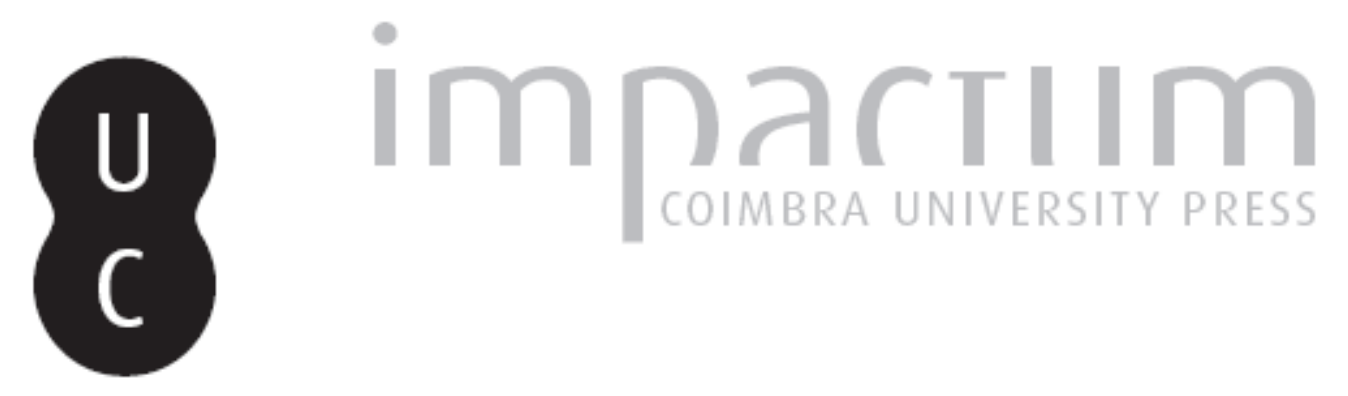

\title{
Cidade sentida
}

\section{Autor(es): $\quad$ Antunes, Inês}

Publicado por: Editorial do Departamento de Arquitectura

URL persistente:

URI:http://hdl.handle.net/10316.2/37222

DOI:

DOI:http://dx.doi.org/10.14195/1647-8681_1_20

Accessed : $\quad$ 26-Apr-2023 10:41:52

A navegação consulta e descarregamento dos títulos inseridos nas Bibliotecas Digitais UC Digitalis, UC Pombalina e UC Impactum, pressupõem a aceitação plena e sem reservas dos Termos e Condições de Uso destas Bibliotecas Digitais, disponíveis em https://digitalis.uc.pt/pt-pt/termos.

Conforme exposto nos referidos Termos e Condições de Uso, o descarregamento de títulos de acesso restrito requer uma licença válida de autorização devendo o utilizador aceder ao(s) documento(s) a partir de um endereço de IP da instituição detentora da supramencionada licença.

Ao utilizador é apenas permitido o descarregamento para uso pessoal, pelo que o emprego do(s) título(s) descarregado(s) para outro fim, designadamente comercial, carece de autorização do respetivo autor ou editor da obra.

Na medida em que todas as obras da UC Digitalis se encontram protegidas pelo Código do Direito de Autor e Direitos Conexos e demais legislação aplicável, toda a cópia, parcial ou total, deste documento, nos casos em que é legalmente admitida, deverá conter ou fazer-se acompanhar por este aviso. 


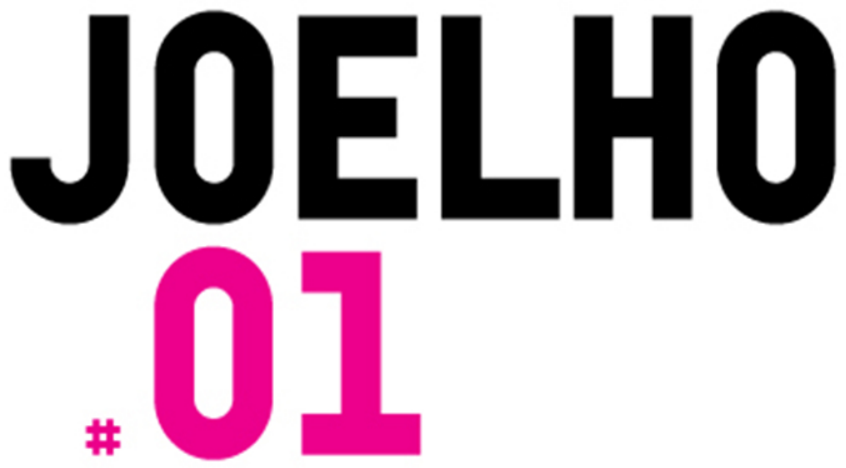

\section{MULHERES NA ARQUITECTURA}

Jorge Figueira

Coordenação

Silvana Rubino

Carla Lopes

Liliana Carvalho

Joana Bem-Haja

Filipa Cabrita

Inês Antunes

Telma Silva

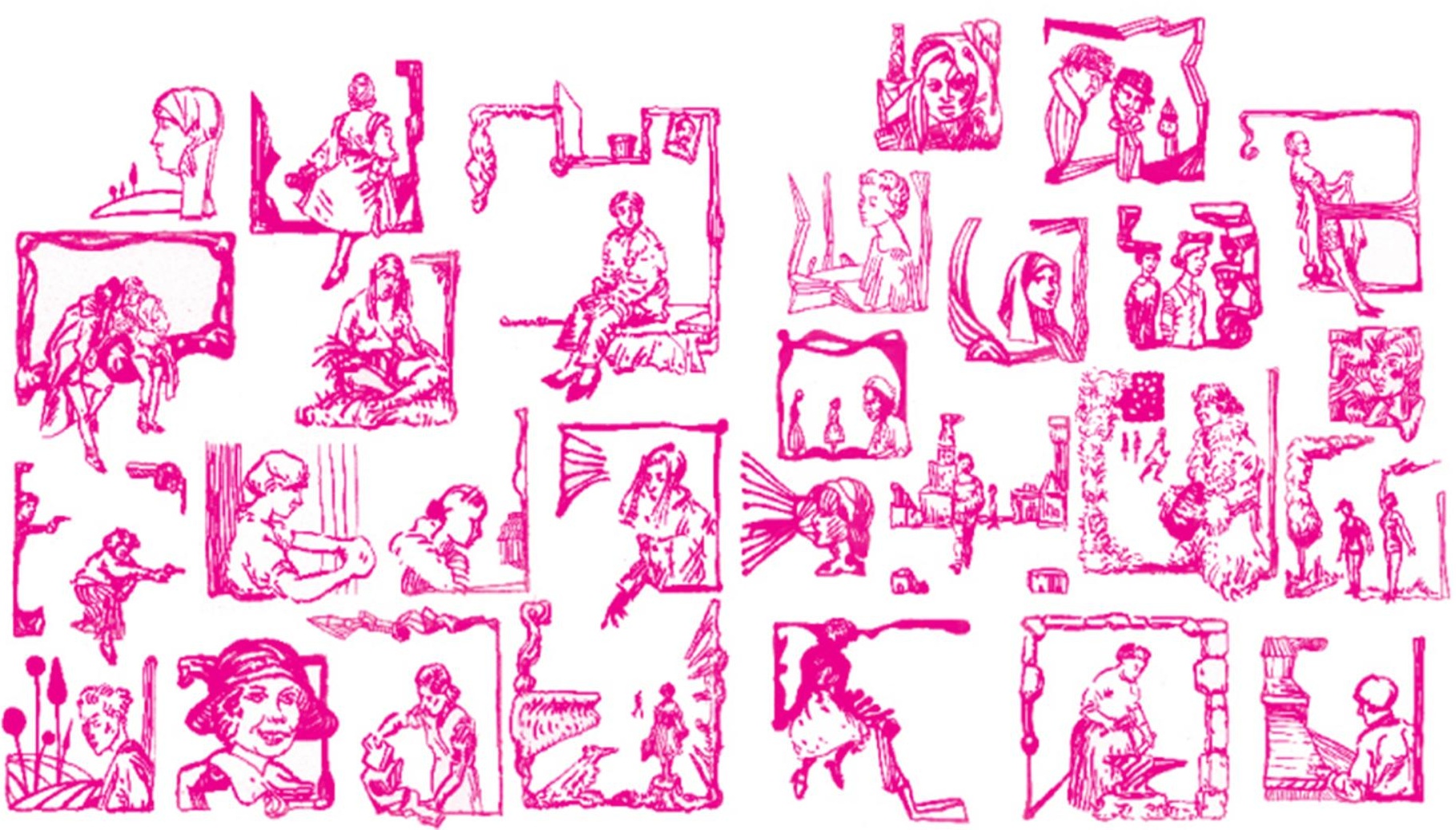




\section{Cidade Sentida}

\section{Inês Antunes}
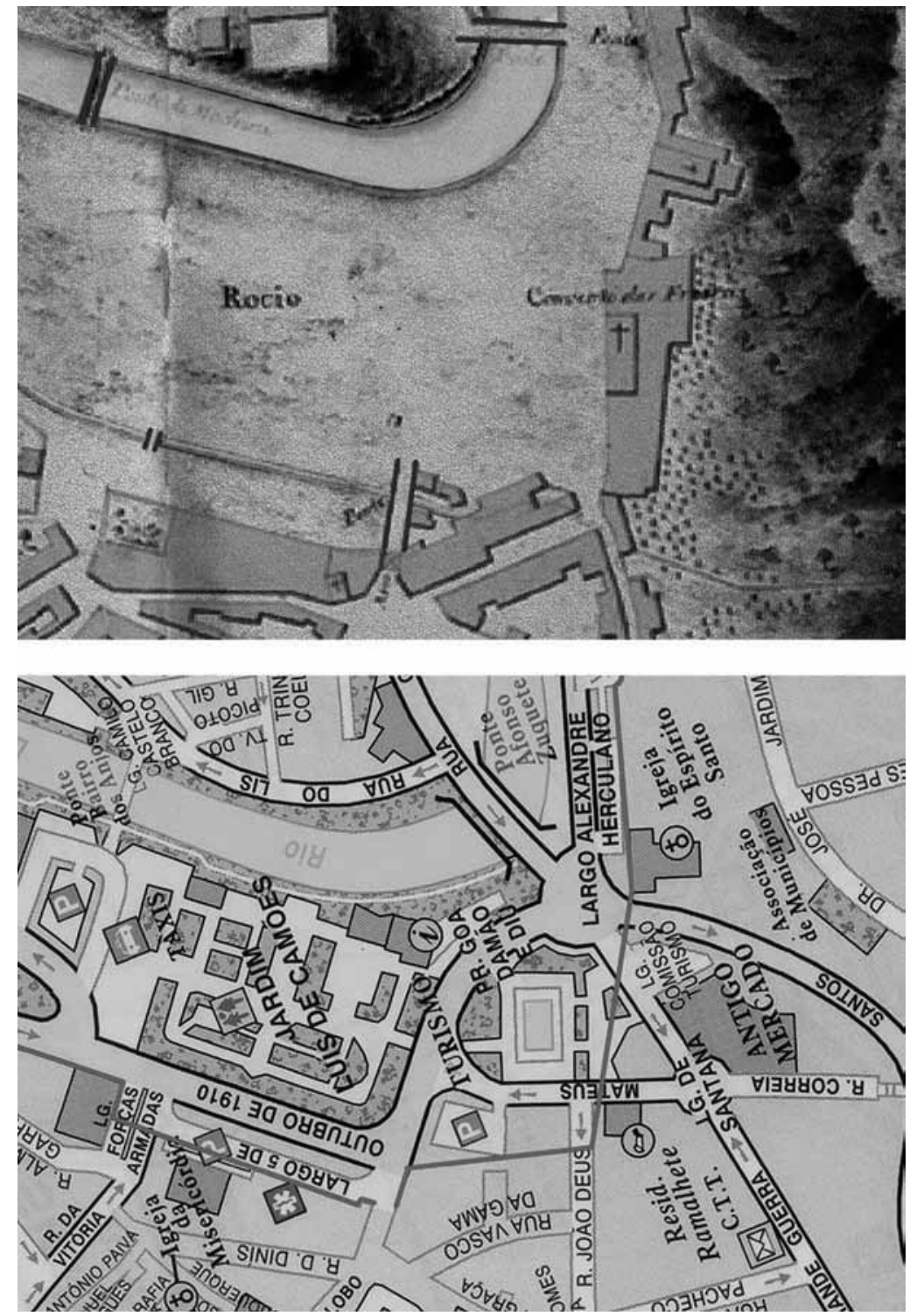

A Cidade de Leiria em 200 anos de história: entre 1809 e 2009 
Cidades são relações; a cidade é concreta quando pensamos no espaço que habitamos, no local de trabalho, no café habitual e em todos os lugares que vivenciamos quotidianamente. É nessa cidade construída que surge outra dimensão incorpórea, dominada pelas representações emotivas do lugar urbano.

A rua, os edifícios e a arquitectura que pontuam a cidade são permanentemente reinventados pelo modo como nos apropriamos desses espaços, impregnando-os de outras perspectivas. Descobrem-se caminhos e segredos, tacteados pelo conhecimento que a cidade tem para contar; histórias dos seus habitantes e das suas idiossincrasias que são o estofo para o encontro do sentido da paisagem urbana. Sentir a cidade é redesenhá-la a partir da posição que cada um ocupa.

Como tal, irrompeu o desejo de revisitar Leiria, a minha própria cidade. Decidi percorrê-la a pé, caminhar... usando a mesma linguagem e método da condição de estrangeiro, desenraizado, para conseguir reconstruir as origens das minhas representações, de uma forma menos superficial. De imediato, deparei-me com uma cidade acumulada: de escalas, de épocas, de intensidades, que foram confluindo ao longo do anos.

A cidade é um conjunto de imagens, de factos e acontecimentos em que o sujeito se revê. Leiria, tal como um indivíduo, tem a sua própria identidade, materializada tanto geograficamente como na proeminência dos valores simbólicos, expressões culturais, históricas e mnemónicas da cidade. Nesta linha de ideias, a cidade não é apenas aquilo que faz ou produz, mas também aquilo que parece, representa e oferece ao cidadão. Leiria é uma cidade com forte carácter patrimonial, desfrutando de uma localização atractiva, centrada num território desenhado por colinas e vales abertos sobre

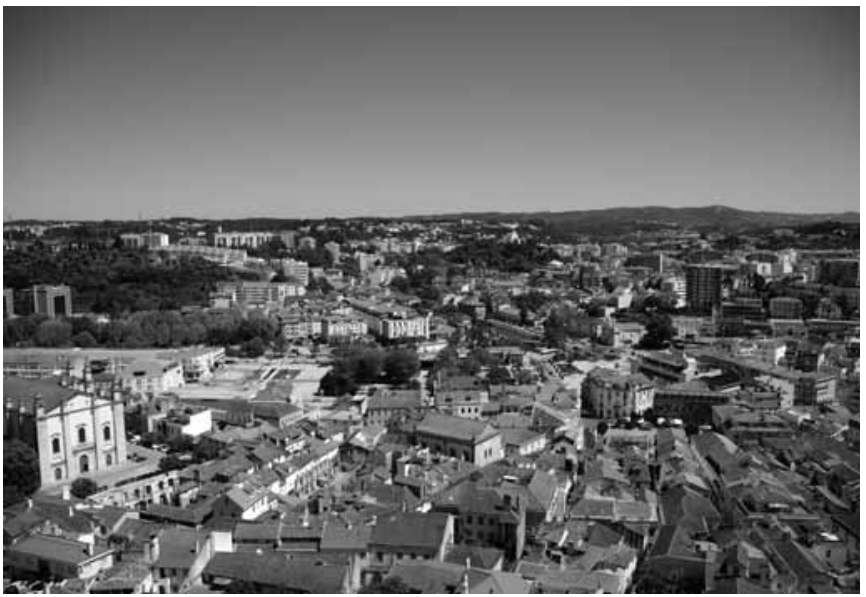

Vista do Castelo sob a Praça Rodrigues Lobo e o Convento de Sant'Ana, em 1870 o rio Lis. Este lugar, entendido como genius loci, traduz uma das características de identidade urbana mais resistentes aos fenómenos de transformação da paisagem urbana. $\mathrm{O}$ fascínio das cidades surge aliado à sua temporalidade $\mathrm{e}$, por isso, a cidade histórica é uma das principais atracções dos dias de hoje. De facto, houve uma deslocação do fascínio dos elementos arquitectónicos físico-espaciais da cidade para a sua história e temporalidade: é na minúcia do exemplar histórico e monumental da cidade que hoje se vislumbram os traços da sua singularidade.

É perante a constatação da materialidade histórica inerente à cidade que Aldo Rossi (Rossi, 1979) procurou uma compreensão da forma enquanto história, na tentativa de recuperar antigas estruturas, presentes na cidade actual. Rossi assinala que a cidade é um dado concreto na sua forma construída, mas essa concretude permite essencialmente entender como a arquitectura constrói a cidade, não só para funcionar mas, sobretudo, para viver e comunicar. "Por arquitectura da cidade podem-se entender dois aspectos diferentes: no primeiro caso, é assimilar a cidade a um grande manufacto, uma obra de 
engenharia e de arquitectura, mais ou menos grande, mais ou menos complexa, que cresce no tempo; no segundo caso, podemo-nos referir a áreas mais limitados da cidade, a factos urbanos caracterizados por uma arquitectura própria, portanto, por uma forma própria. Nos dois casos, percebemos por uma sua arquitectura e, portanto, por uma forma" (Rossi, I979: 44).

O sujeito não se identifica com estruturas abstractas mas com um mundo de coisas palpáveis que se reconhecem e se recordam. O carácter ambiental é determinado pelos objectos que constituem a cidade enquanto património urbano. A história de Leiria está marcada por estes exemplos. É no centro histórico que se concentra a maior parte deste edificado, um verdadeiro memorial colectivo da cidade. Assim, a identidade urbana pode ser lida como a materialização de memórias múltiplas, resultado de tempos diversos.

A ocupação do lugar de Leiria é precedente à época medieval. Porém, só no século XI I se dá a sedentarização e consequente ocupação na região. A cidade permanece sobre os seus eixos de desenvolvimento, mantendo a posição progenitora nos seus traçados, crescendo sob a direcção e o significado de um facto primordial, o Castelo. Cada cultura pode assim ser identificada e reconhecida pelos seus edifícios mais marcantes que adquirem dessa sociedade, a composição e formação da própria estrutura e expressão do seu poder simbólico. Na verdade, o Castelo alcança uma importante conotatividade, na medida em que comprova e identifica o passado e a sua organização espacial, propondo às gerações vindouras uma importante ligação com o testemunho de uma época histórica: de fortaleza militar, a palácio real, a monumento turístico. Apesar de não ter sido concebido com a intenção de ser um ícone, a cidade, a desenvolver-se à sua volta, manteve o Castelo em destaque. A sua forma clara e única provocam na envolvente citadina um imensurável contraste, quer pela forma quer pela história. "Quem, chegado a Leiria, inesperadamente depara com a formosa silhouette do castello, sente-se penetrado de um vivo sentimento de admiração pelo aspecto pittoresco d'aquellas históricas ruínas" (Korrodi, 2009: II I). O Castelo é o monumento mais característico da identidade leiriense, das memórias de um tempo passado, das conquistas e das guerras com os mouros, aquando da sua fundação no reinado de D. Afonso Henriques, no século xi I. Dominante sobre a cidade, o Castelo tem na sua génese condições fisiográficas e geográficas, de implantação dos primeiros habitantes: o cimo de um escarpado monte, a Norte, e a Sul, o rio Lis. A ocupação do espaço intramuros inicia-se logo após a sua construção, esmorecendo no final do mesmo século, aquando da fixação do poder religioso e a sedimentação do povo junto das igrejas.

A cidade de Leiria aconchegava-se assim, aos pés do Castelo, crescia e aproximava-se cada vez mais do leito do rio Lis. Isto é, a expansão urbana até ao século XVI ainda se manteve confinada entre dois elementos naturais que foram relevantes na sua génese e desenvolvimento do aglomerado: o morro do Castelo, onde foi implantado o núcleo genético e o rio, factor de crescimento, principalmente a partir do século xiıI. Com o passar dos anos, a cidade expandiu-se para lá do rio Lis, "andava então a construir-se a estrada da Figueira: o velho passadiço de pau sobre a ribeira do Lis tinha sido destruída, 
já se passava sobre a Ponte Nova.(...) Da Ponte pouco se vê da cidade; apenas uma esquina das cantarias pesadas e jesuítas da Sé, (...) o resto está escondido pelo duro monte ouriçado de vegetação rebeldes, onde se destacam as ruínas do Castelo, todas envolvidas à tarde nos largos voos circulares dos mochos, desmantelados e com um grande ar histórico" (Queirós, I993: 9). E as marcas de ruralidade foram desaparecendo, fixando na arquitectura vários acontecimentos determinantes. Para além da igreja, Leiria iniciava as suas primeiras construções públicas, muitas delas ainda hoje vigentes, tornando-se uma máquina em constante mutação.

As transformações morfológicas de Leiria aconteceram em função de dois importantes empreendimentos arquitectónicos: a abertura da Praça de São Martinho - denominada anos mais tarde por Praça Rodrigues Lobo - e a construção da Sé Catedral. Se o Rossio foi a zona de recepção da cidade, com o seu ajustamento aos campos rurais e ponto de chegada dos visitantes, a Praça foi o primeiro aglomerado urbano, demarcado num quadrilátero e circunscrito por um conjunto arquitectónico de arcadas e galerias que eram o espaço preferido para a cavaqueira e a má-língua. A presença desta gerou a abertura de novas ruas e a criação de um novo espaço público de lazer, o Rossio, em torno da Praça, proliferando, cada vez mais, o adensamento populacional da cidade de Leiria. A abertura do Passeio Público junto ao leito do rio Lis, agregaram na Leiria de então, a Sé Catedral, o Paço Episcopal, a Praça, o Convento Sant'Ana e a já distante Igreja da Misericórdia. A proximidade de todos estes aglomerados perante o rio gerou a principal via de acesso da cidade com os seus limítrofes, facilitando as deslocações e a expansão comercial urbana. Segundo Ana Paula Margarido, "a cidade seiscentista organizou-se, assim, preferencialmente junto da Praça e as construções que ladeavam as

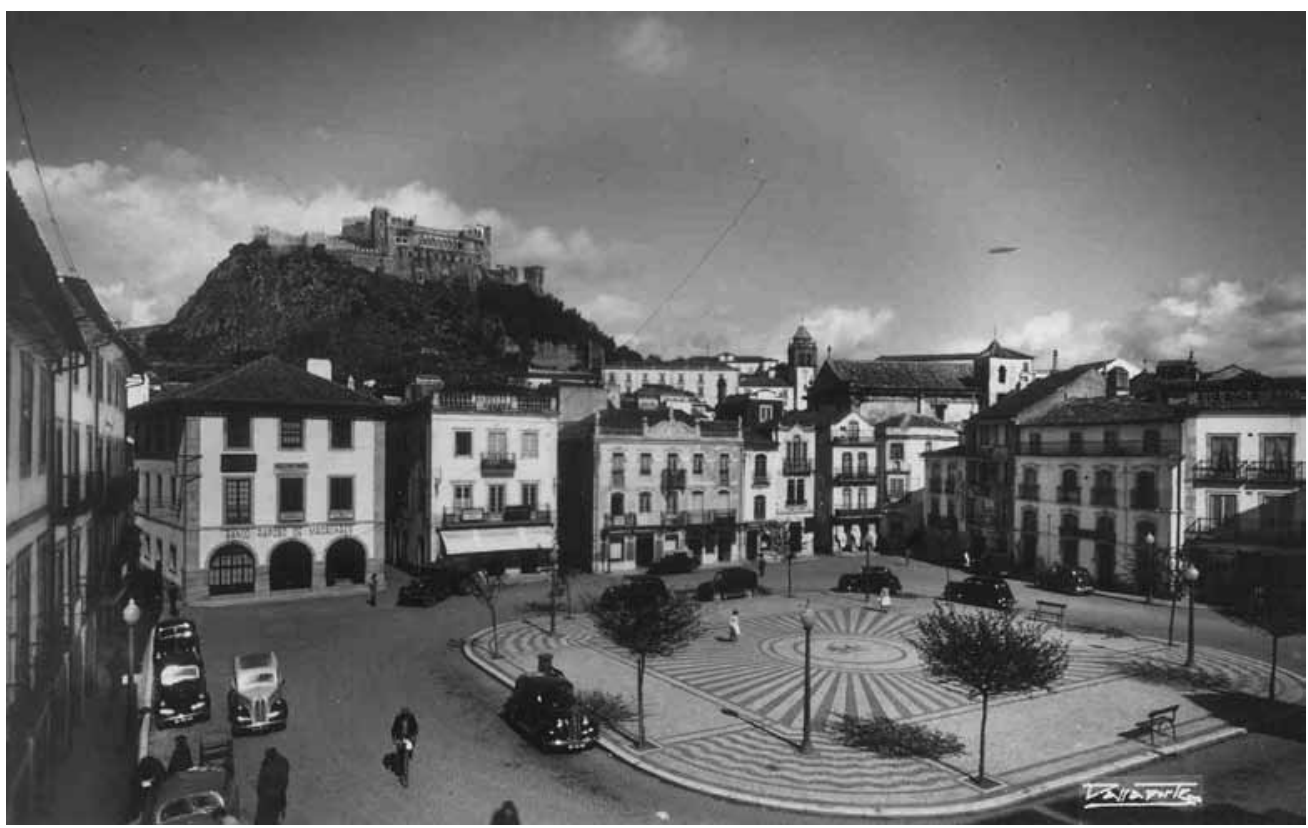

Vista do Castelo sob a Praça e o Convento de Sant'Ana, em 1909. É visível o desenvolvimento da cidade nesses anos, bem como a demolição do Palácio dos Marqueses de Vila Real e a construção do Teatro D. Maria II 


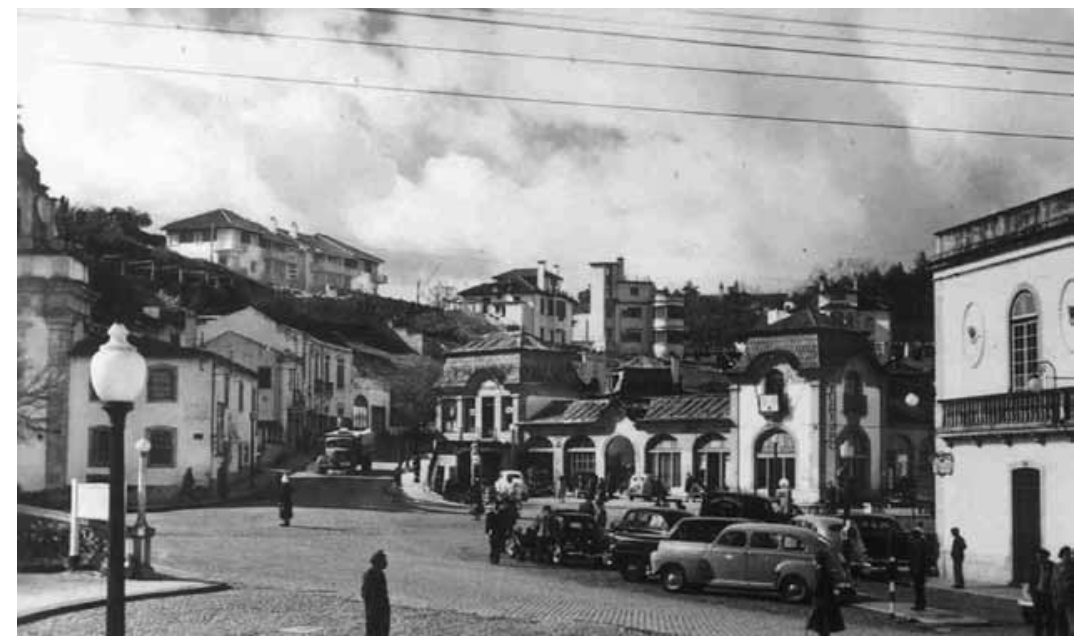

A Praça Rodrigues Lobo, em 1915

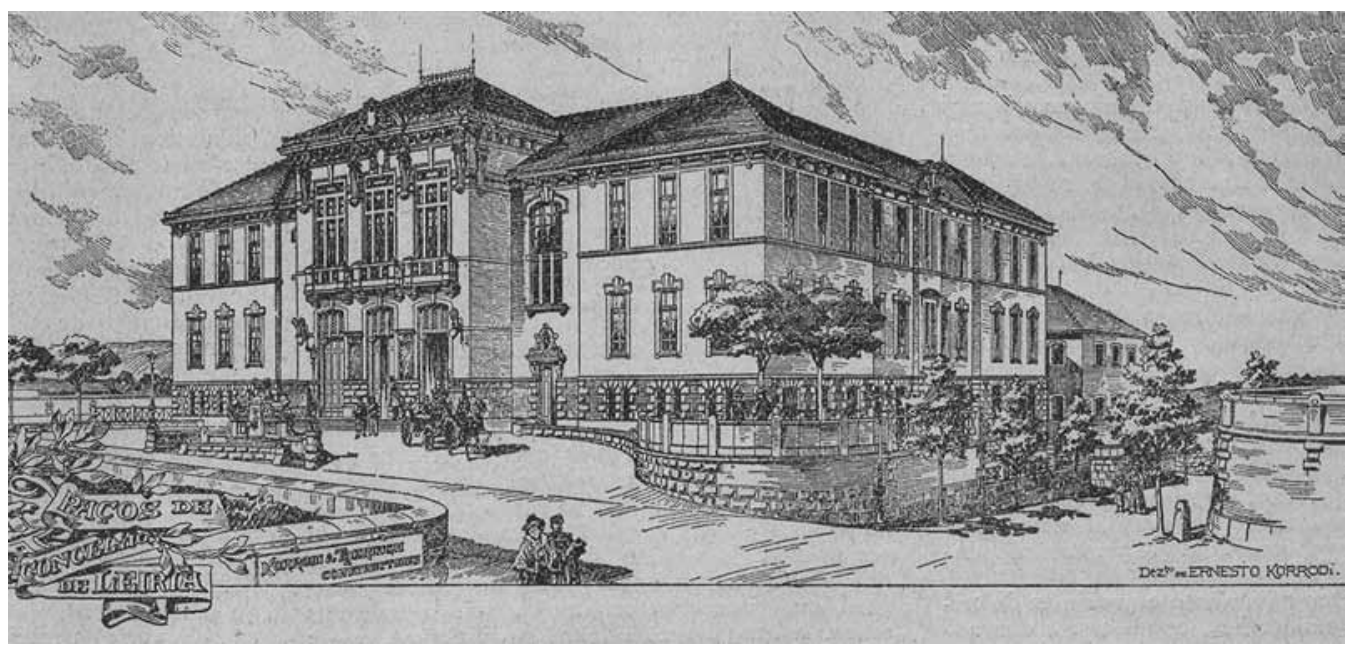

Os Paços do Concelho, em 1897. O edifício foi concebido na intenção de funcionar como Câmara, Tribunal e Cadeia da Cidade de Leiria

ruas que a envolviam foram crescendo, tornando o espaço urbano cada vez mais compacto. Era ainda na Praça de S. Martinho que se localizava a casa da Câmara e o Pelourinho da dignidade concelhia" (Margarido, ı988: 56).

Perante o empenho de urbanizar, foram feitas no século XIX importantes obras de requalificação urbana, com vista a dotar este espaço de um cunho mais urbano, tentando apagar ou dissimular as marcas da ruralidade. Aos poucos, o Rossio transformava-se; numa primeira fase é arborizado e já no final do século XIX é aberto o passeio público, passando esta zona a ser um dos pontos mais nobres da cidade. Por esta altura foram plantadas diversas árvores na margem esquerda do Lis, surgindo duas filas que formavam uma interessante mancha verde, na fantasia romântica do Passeio Público, com o seu coreto de armação de ferro e a assimetria sinuosa dos canteiros e recantos ajardinados. É a primeira visão que, no livro de Eça de Queirós, o "Padre Amaro" tem quando desce da diligência: 
"na longa alameda macadamizada que vai junto ao rio, entre os dois renques de velhos choupos, entreviam-se vestidos claros de senhoras passeando. Do lado do Arco, na correnteza de casebres pobres, velhas fiavam à porta: crianças sujas brincavam pelo chão, mostrando os seus enormes ventres nus; e galinhas em redor iam picando vorazmente as imundices esquecidas. Em redor do chafariz cheio de ruído, onde os cântaros arrastam sobre a pedra, criadas ralham, soldados, com a sua fardeta suja, enormes botas cambadas, namoravam, meneando a chibata de junco; (...) Já tinha anoitecido quando a diligência, com as lanternas acesas, entrou na Ponte ao trote esgalgado (...), e veio parar ao pé do chafariz por debaixo da estalagem do Cruz; o caixeiro do tio Patrício partiu logo a correr para a Praça” (Queirós, 1993: I4-15).

A cidade crescia velozmente. A ligação entre o Rossio e a Praça resultava da demolição do arco e ponte do Palácio do Marquês de Vila Real, com a construção de dois novos edifícios, com frente para a Praça e para o campo D. Luís I. Entretanto, em I88o, com a construção do Teatro D. Maria II, em frente à Igreja, alterou-se bastante a configuração da zona citadina, reduzindo o espaço do mercado em frente ao Rossio e retirando a fachada do Convento dos horizontes imediatos da cidade. Perante o cenário pitoresco do Passeio Público, aquando a construção de alguns dos edifícios mais emblemáticos, pelo comando do arquitecto Ernesto Korrodi, a Praça passou a praticar outro tipo de comércio, que se instalava no rés-do-chão dos edifícios, cingida pelas inúmeras lojas e cafés, ainda hoje presentes, privilegiando o espaço superior para habitação colectiva. Na verdade, a Praça, ainda hoje símbolo de colectividade, continua a ser o coração de Leiria. Continua a ser ainda a "Praça" por excelência, a única na cidade que conserva viva a tradição e a herança de um programa urbanístico passado.

A reconversão e requalificação na cidade de Leiria é o método que permite conservar e manter vivo o património, tendo pouco significado as novas intervenções de raiz, mesmo que inseridas da cidade histórica. É neste predito que surge o Edifício do Mercado Sant'Ana, antigo Convento reconvertido em Mercado. Esta requalificação significa atribuir-lhe um novo uso, diferente daquele para o qual foi pensado, implicando considerar a sua vocação espacial para responder ao respectivo programa. Sem se pretender historiar de modo exaustivo a evolução do espaço que precedeu a construção do Mercado de Sant'Ana, obra de Ernesto Korrodi, seria ilícito ignorar uma série de modelações que foram determinantes no actual perfil da cidade. A principal razão que levou à expansão de Leiria para leste, ainda no período medieval, foi a configuração das estradas de ligação com a via principal Lisboa - Porto e a via secundária para a Batalha, ambas seguindo o traçado das antigas vias romanas. A primeira saía para Norte atravessando a ponte em frente à Igreja do Espírito Santo; a segunda acompanhava os campos do Lis junto à fábrica de papel que aí existia nos começos do século xv. O Convento, mosteiro religioso da observância de S. Domingos, foi construído no final do século xv, ficando conhecido por Convento e cerca de Sant'Ana. 
Os escassos vestígios e relatos existentes reportam para uma construção sem grande monumentalidade, no qual as monjas, em virtude da gradual baixa de rendimentos, subsistiam com grandes dificuldades.

Nos finais do século XIX, o crescimento urbano impõe um novo olhar sobre a cidade. As dinâmicas económicas e sociais emergentes reclamavam pela conversão do Convento, espaço religioso e rústico, numa área urbana e comercial. Perante tal situação, a Câmara no início do século xx adquiriu o edifício, mandando elaborar um Plano de Urbanização a Ernesto Korrodi, envolvendo o vasto espaço no qual se iria situar o futuro Mercado Sant'Ana. O Plano concebia uma nova Praça e o edifício do Mercado, que era circunscrito por uma rua pedonal, de acesso secundário ao Mercado e uma rua que o confinava à actual Rua dos Combatentes da Grande Guerra, que iria ligar o centro histórico ao alto da Portela, onde se situava os também recentes Paços do Concelho. É neste contexto que aparece o Mercado de Sant'Ana construído e inaugurado em 1931.

Ernesto Korrodi que conheceu o Convento de Sant'Ana não quis ignorar a imagem deste, quando planeou o Mercado. Ao construir as quatro torres que lhe delimitam o espaço, infiltrou-lhes uma memória barroca subjacente ao desenho de Arte Nova e configurou-as como campanários para que a população dos arredores mantivesse a ilusão de continuar em plena urbe, a usufruir do aconchego do adro da aldeia. Interiormente, no local preciso onde se situava o claustro do Convento, desenvolveu uma série de arcadas de alvenaria, numa assumida reivindicação da persistência das formas precedentes, como que, para se fazer perdoar da rudeza de uma intervenção algo sacrílega num momento de pujança do laicismo republicano. As lojas que ladeavam o edifício foram envidraçadas de ambos os lados, para aumentar a transparência do local e misturar o espírito do Mercado à nova Praça. Com êxito, a Praça de Santana viu-se rodeada de hotéis, cafés e instituições bancárias, atraindo temporariamente a população como se um novo centro urbano despontasse.

$\mathrm{Na}$ realidade, Ernesto Korrodi surge com um papel extremamente activo no engagement da arquitectura em Leiria, trazendo à cidade uma nova imagem, envolvida e materializada pela sua linguagem erudita, na maior parte das vezes inspirada em cânones maneiristas ou barrocos, num processo de assimilação da expressão formal e dos valores espaciais da arquitectura tradicional portuguesa. Como arquitecto e autodidacta, Korrodi era considerado um artista de uma grande e fina sensibilidade, extraordinário a desenhar, passando para o papel não só o que objectivamente via como ainda impregnava esses seus desenhos da alma e da poesia que o seu sentimento tão bem subjectivava e transmitia. Este apego pela imagem de arquitectura, referenciada tanto a um passado imaginário como ao presente, permaneceu na sua obra, sempre mais directamente ligado a valores estéticos e pictóricos do que à modelação de espaços e de volumes. Esta característica korrodiana permitiu, por um lado, fixar a sua obra numa determinada época - um século XIX tardiamente romântico e cenográfico -, e, por outro lado, explicou o seu ecletismo que absorve uma série de imagens que o desenho sempre retinha.

A sua formação como escultor/decorador, leva-o a integrar a decoração na arquitectura de uma forma inovadora. Nessa relação entre a forma 
e o ornamento definir-se-ia o seu estilo pessoal, "numa arquitectura que ele pretendia sóbria e sobretudo clara no enunciado dos seus volumes. Aproximando-se, nos seus valores espaciais, de um programa semelhante ao Domestic Revival Inglês, movimento na qual a sua formação ganha sentido, a sua obra evoluiria dentro de um certo aportuguesamento, nos seus valores decorativos e/ou arquitectónicos, com uma especial atenção para as épocas maneiristas ou barrocas. (...) Romântica pela sua vigência no tempo, mas Nova pela renovação que trazia à linguagem decorativa, afastando-se dos cânones clássicos, e ao novo diálogo que estabelecia entre a forma e a decoração, do qual resultaria uma relação estilística renovadora. (...) Artista de pedra o seria sempre Ernesto Korrodi e, nesse aspecto, ele permanecerá um arquitecto ligado à tradição, dentro do qual se processou o seu entendimento da Arte Nova" (Costa, I997: 304). No caso de Camilo Korrodi, seu filho e arquitecto, este engagement é pautado pela larga intervenção arquitectónica, sobretudo ao longo das novas avenidas de expansão da cidade. A sua marca sobressai em duas zonas importantes da cidade, envolvendo duas importantes artérias: a Avenida dos Combatentes da Grande Guerra e a Avenida Heróis de Angola. $\mathrm{O}$ traçado da primeira e os arruamentos circundantes resultaram da demolição do antigo convento Sant'Ana, dando lugar ao actual Largo de Santana e os arruamentos envolventes. Este plano, iniciado em I903, teve um longo processo de consolidação da malha urbana, onde é possível verificar uma grande variedade de intervenções desde os anos 30 aos anos 6o, na obra de Camilo. A Avenida Heróis de Angola, embora aberta já desde 1938, fará parte do plano do arquitecto Lima Franco que, em I945, fora contratado pelo município para projectar o Plano Geral de Urbanização da Cidade. A Avenida ligava assim, o Largo 5 de Outubro ao Convento de S. Francisco expandindo a cidade para norte. Dentro do espírito de urbanismo do Estado Novo, o plano privilegiava uma lógica de quarteirão cujo carácter unitário do conjunto da avenida deve-se, em grande parte, aos diversos edifícios projectados por Camilo, destacando, assim, todo o conjunto da Rodoviária e uma série de Blocos de Rendimento, desenvolvidos maioritariamente nos anos 60.

No contexto geral de toda a intervenção do legado Korrodi em Leiria, é possível perceber a primazia destes arquitectos na actual imagem da cidade. Embora demonstre uma grande heterogeneidade de intervenções, estas acompanham não só a sua notória evolução e maturidade, mas também o evoluir da cidade no tempo, quer a nível social, quer a nível arquitectónico.

Não podemos voltar atrás ou projectar num cenário passado, por isso é necessário encarar os estilos e as tradições antigas como factores que devem estar patentes na continuidade formal e estrutural da cidade. Deste modo, à arquitectura cabe construir a cidade e mais especificamente responder à cidade construída, através da articulação resultante do confronto temporal. A arquitectura pode assim recuperar o seu protagonismo na cidade, interpretando as regras e morfologias existentes, acrescentando inteligência e sensualidade ao lugar. Associada à transformação e consolidação da cidade, a arquitectura não deixa de ser sensitiva pela forma, pela escala e pela sua linguagem. A arquitectura constitui o corpo da cidade; o edifício modela e estrutura o tecido urbano. 
É necessário conhecer o passado histórico arquitectónico como componente activa da cultura actual, não apenas pela sua aceitação passiva mas sobretudo através de uma atitude critica, um comportamento vinculativo com a história de Leiria. A cidade acumula as memórias e os sonhos de todos os passados na dimensão única do presente. Leiria não é a mesma sem Eça de Queirós ou Francisco Rodrigues Lobo. Cidade de lendas e poetas, a saudade e o bucolismo é um dos temas constantes na prosa Leiriense. Recua-se, por instantes, ao século XVII, tempo em que Leiria contava entre os seus naturais com um dos maiores vultos da literatura portuguesa de então, Francisco Rodrigues Lobo. Em "Pastor Peregrino" captou com rara percepção a paisagem de Leiria: "mais fresca e abundante que em teus dias podes ter habitado; a qual regam dois graciosos rios que, junto à cabana onde eu vivo, entram no mar em companhia; a um deles chamam Lis e a outro Lena, que, postos que não sejam nomeados no mundo pela sua corrente, como são graciosos e alegres pelos seus arvoredos, mereciam todos os louvores que os outros alcançaram pela sua grandeza" (Lobo, 2004: 300).

Passa-se muito tempo até Leiria reaparecer de novo nas letras portuguesas. Eça de Queirós, romancista e administrador governamental, fez desenrolar na cidade toda a trama de O Crime do Padre Amaro. Por cá, retrata com algum realismo a sociedade leiriense, criticando impiedosamente os costumes do clero português, e atacando sarcasticamente através de Amélia, os religiosos. De facto, quem tiver o prazer de percorrer alguns dos espaços da obra, aperceber-se-á da recorrência a determinados locais ainda hoje identificáveis. A Ponte Nova, a Sé, as ruínas do Castelo, a Estrada dos Marrazes, a Rua da Misericórdia...

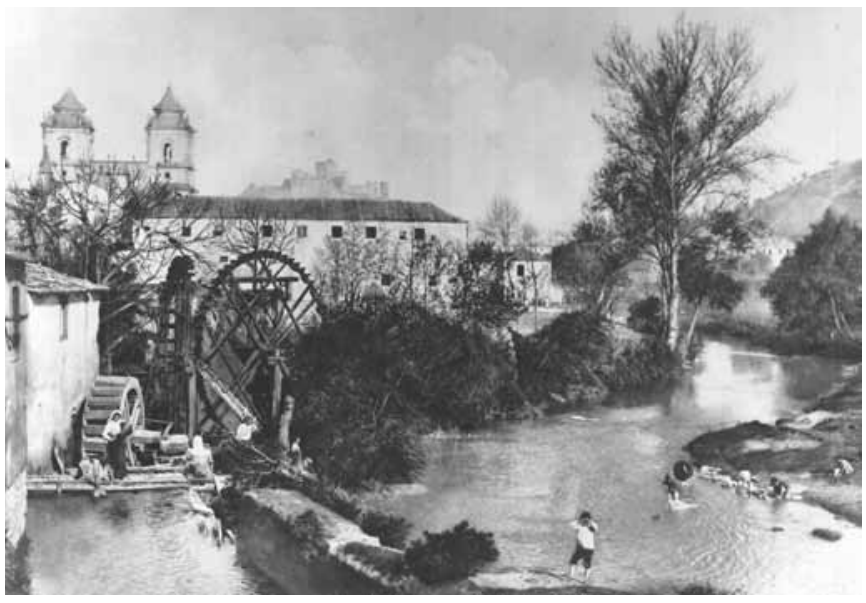

Moinho de Papel

Perante estas constatações das Artes e da História, Leiria é também palco de expressão operária. Cada cidade possui uma identidade que poderá existir na sua origem ou ser desenvolvida por agentes sociais que, no tempo, a habitam, governam e produzem. Surgem assim diferentes identidades urbanas, as cidades-porto, as cidades-fortaleza, a cidade-indústria. Leiria desde sempre se globalizou e impôs a sua marca económica perante todo o País. "Está sobejamente provado que Leiria pode orgulhar-se de ter sido a terra portuguesa onde, pela primeira vês, se fabricou papel" (Margarido, I988: 23). No século xv, a primeira fábrica de Papel - Moinho de Papel, como é denominado actualmente - era implantada junto às margens do Rio Lis perante a imposição de D. João I para que se instalasse, junto à ponte dos Caniços, um moinho para desenvolver actividades ligadas à transformação de cereal, do papel ou outras coisas que se pudessem fazer com o artificio da água. A indústria era recente e a situação privilegiada de Leiria na sociedade portuguesa da época fizeram com que, com o seu Moinho de Papel, fosse a primeira cidade "de todas as Espanhas" (Cabral, I993: 55) a ter imprensa. A cidade do Quatrocentos era já comunicante, nela se imprimiam os mais antigos incunábulos portugueses. 
Contudo, para além da obrigatória fotografia, visita ou descrição mnemónicas da cidade de Leiria, poder-se-á questionar quantas pessoas realmente compreenderão o impacto do centro histórico no contexto urbano mais alargado ou qual o seu significado na história da cidade. Na contemporaneidade, surge como se se tratasse de um prestigioso cenário intocável. Se assim é, o que representa hoje, para os habitantes de Leiria, o centro histórico? A resposta depende dos grupos etários: para as pessoas que vão tomar café à Praça aos domingos, num ritual já de memória feito, o centro histórico traduz o apego às imagens de um passado próximo da cidade; para outros o centro é quase ignorado, numa já diluída identidade citadina. Certo é que o poder representativo que estas estruturas representam na cidade, irradiam e identificam-na. $\mathrm{Na}$ verdade, esta singularidade urbana reside na diversidade de experiências quotidianas oferecidas na produção, circulação e bem-estar pessoal. É precisamente com esta riqueza que surgem em Leiria espaços magníficos, cingidos pelos vales e pelo rio Lis, numa profusa acumulação de escalas, densidades, épocas e arquitecturas.

De facto, cada vez mais, as pessoas encontram na cidade o palco e a história das suas vidas. A cidade deixou de ser definida como lugar que alberga sujeitos, hoje as pessoas são e fazem as cidades: a cidade de uma Pessoa não será igual a de nenhuma outra. É necessário entender o outro através do que se vê dentro de si próprio. Cada cidade, apesar das suas similitudes - em elementos visuais, sonoros e olfactivos distintos - para com a outra, não deixará de ser única.

\section{Referências bibliográficas}

Cabral, João (1993), Anais do município de Leiria. Leiria: Edição Câmara Municipal de Leiria [vol. 1, $2^{\mathrm{a}}$.ed.].

$-$

Costa, Lucília Verdelho da (1997), Ernesto Korrodi: 1889-1944 - arquitectura, ensino e restauro do património. Lisboa: Estampa.

Korrodi, Ernesto (2009), Estudos da reconstrução sobre o castelo de Leiria. Leiria: Imagens \& Letras [1898].

Lobo, Francisco Rodrigues (2004), Pastor Peregrino. Lisboa: Vega Editora.

-

Margarido, Ana Paula (1988), Leiria: história e morfologia urbana. Leiria: Câmara Municipal de Leiria.

-

Queirós, Eça de (1993), O crime do padre Amaro. Lisboa: Círculo de Leitores.

Rossi, Aldo (1979), A arquitectura da cidade. Lisboa: Edições Cosmos.

\section{Créditos das imagens}

A Cidade de Leiria em 200 anos de história: entre 1809 e 2009 (Inês Antunes)

-

Vista do Castelo sob a Praça Rodrigues Lobo e o Convento de Sant'Ana, em 1870. Fotografia de Jorge Estrela

Vista do Castelo sob a Praça e o Convento de Sant'Ana, em 1909. É visível o desenvolvimento da cidade nesses anos, bem como a demolição do Palácio dos Marqueses de Vila Real e a construção do Teatro D. Maria II. Fotografia de Jorge Estrela

A Praça Rodrigues Lobo, em 1915. Fotografia de Jorge Estrela

-

Os Paços do Concelho, em 1897. O edifício foi concebido na intenção de funcionar como Câmara, Tribunal e Cadeia da Cidade de Leiria. Fotografia de Jorge Estrela
O Mercado Sant'Ana em 1940. O Edifício albergava o então Mercado do "Peixe" e o Posto de Turismo da Cidade. Fotografia de Jorge Estrela

Moinho de Papel. Fotografia de Jorge Estrela 